\title{
NOTAS
}




\section{CRISIS DE LA EDUCACION E INVESTIGACION EN EPOCA DE CRISIS}

\section{Jorge González Rojas}

La Educación en Colombia está en crisis. La educación está en crisis en muchos lugares del mundo. ¿Sólo la educación? No. La familia está en crisis; la economía lo está; la Administración de justicia y la juventud también. Ante estas impresiones se puede presumir que nuestro sistema social en su funcionamiento total está en crisis.

Se impone la necesidad de reflexionar sobre la crisis, asumirla, enfrentarla intentar manejarla. En esta toma de posición radica el éxito de una de las proposiciones más difundidas actualmente en el mundo occidental: adaptamos a la época turbulenta buscando la "excelencia" pero ¿cómo hacerlo en nuestro caso?

Lo que sigue constituye un punto de vista sobre la crisis, una manera de pensar la crisis. Es el reconocimiento de la desorganización y reorganización permanente del mundo, ante la cual surge la necesidad de buscar un lugar de apoyo desde donde ensayar la estructuración normativa que nos proporcione una seguridad transitoria.

Pensar la crisis, enfrentar la crisis, he ahí una actitud necesaria para iniciar la búsqueda sin término de nuevas formas de construir nuestra cotidianeidad que respondan a la desestructuración normativa, constante en nuestras instituciones.

En este contexto queremos incluir el debate que origina la situación actual de nuestra educación y el papel de la investigación en este caso. Para tal efecto, iniciamos caracterizando la realidad que pretende tematizar.

Aceptamos con W. Dilthey que la historia de la educación obedece a dos factores que se determinan mutuamente. Por una parte, el avance de la Ciencia determina los medios de la educación. De otra parte, el estado cultural de una generación determinada constituirá el fin de la educación. El fin que persigue la educación lo sintetiza este autor en la expresión "Ideal de Formación”, el cual depende del ideal de vida de la generación que educa $^{95}$.

En la historia reciente, el sistema de las sociedades modernas se ha consolidado luego de tres grandes revoluciones: La revolución democrática, la revolución industrial y la revolución educativa. La organicidad y la cohesión de la comunidad societaria implica una determinación mutua de esos tres momentos evolutivos. Con mayor énfasis la relación entre la industria y la ciencia se acentúa a partir de la revolución industrial. Luego del último cuarto del siglo pasado se comprueba que la ciencia y la técnica constituyen la primera fuerza de producción.

Una de las implicaciones de este fenómeno (revolución científico-técnica) consiste en la posibilidad de que esta nueva orientación del trabajo científico con todas sus connotaciones, penetre y determine el "Ideal de Formación". Si atendemos a la característica del trabajo científico, en tanto que forma particular de trabajo, como

\footnotetext{
* Sociólogo MS. Psicólogo (c) Ph.D. Profesor de la Facultad de Artes y Humanidades. Universidad Pedagógica Nacional.

${ }^{95}$ Dilthey, W. Historia de la Pedagogía. 7a. Edic. Bs. As: Losada, 1965 (pp. 15-16).
} 
actividad racional por finalidad, se puede presentar la tentación de comprender el acto educativo única y exclusivamente como actividad racional por finalidad que obedece a normas técnicas y cuya forma de proceder es principalmente por medio de "estrategias basadas en un saber analítico, que implica la deducción de reglas preferenciales (sistemas de valores)" ${ }^{\prime \prime 6}$.

Este determinismo científico de la realidad educativa desplaza o minimiza un aspecto que a nuestro juicio resulta fundamental para pensar la crisis. La realidad de la cual forma parte nuestra realidad educativa está constituido por interacciones sociales, las cuales corresponden a procesos de comunicación que se adaptan a normas obligatorias prevalentes, cuyo valor "se basa exclusivamente en la intersubjetividad de la comprensión de las interacciones y está asegurado por el reconocimiento general de las obligaciones" 97 .

El anterior argumento se constituye en un punto fundamental para nuestras reflexiones sobre la crisis educativa, dado que las normas sociales dominantes en el desarrollo histórico de nuestras instituciones están en crisis.

¿Cómo puede, entonces, consolidarse el "Ideal de Formación” en estas circunstancias? ¿Cuál es el proyecto social, político y económico de la generación que forma a nuestros educandos? Es posible que para construir las respuestas a estos interrogantes se imponga la necesidad de replantear la actividad investigativa y educativa.

¿Cuál puede ser el papel de la investigación educativa en tales circunstancias? En primer término es necesario el reconocimiento de la complejidad de los problemas relacionados con la educación, como debe suceder con cualquier otro evento social. Este reconocimiento nos permite aproximarnos a la pluridimensionalidad de este orden de realidad; a partir de la múltiple determinación de los hechos educativos se han creado los espacios de reflexión que comúnmente se denominan "Ciencias de la Educación", disciplinas que en forma consuetudinaria quieren hacer parte de las ciencias llamadas nomotéticas.

Cuando hablemos de Ciencias de la Educación pensamos en la Psicología, la Sociología, la Lingüística, la Antropología, entre otras, todas ellas ciencias sistemáticas de la acción que tienen como objetivo, determinar las leyes que regulan la acción (conocimiento nomotético).

Si consideramos en su inextricable complejidad la realidad educativa, encontramos que su rasgo distintivo consiste en estar conformada por interacciones sociales. Esta característica conduce a la coexistencia de las disciplinas histórico-hermenéuticas con las Ciencias nomológicas. En la actividad histórico hermenéutica la búsqueda se dirige hacia la comprensión del sentido de la acción.

Esta complementariedad en las ciencias de la educación puede originar una pluralidad de intereses, por una parte, las ciencias nomológicas (sistemáticas de la acción) se guían con frecuencia por un interés técnico. Según j. Habermas, estas disciplinas nos dotan de las prácticas que permiten estar en capacidad de resolver problemas. Consignemos la anotación de Schnäidelbach a la proposición anterior, en el sentido de distinguir entre 'acción técnica, que es una unidad no problematizada de persuasión y hábito de

\footnotetext{
${ }^{96}$ Habermas, J. La técnica y la ciencia como ideología. En: Revista Eco XXII, (1) Nov. 1970 (p. 10)

${ }^{97}$ Ibid (p.11).
} 
conducta, y acción experimental que problematiza esa unidad y la toma como ocasión de investigación"98.

En estas condiciones el papel de la investigación educativa es múltiple: precisar el sentido de la acción, tanto como dotarnos de un saber empírico-analítico que nos posibilite resolver nuestros problemas. Reconocer la crisis, identificar sus múltiples causas, desarrollar acciones experimentales, en síntesis, construir nuevos espacios de equilibrio a partir del estudio de la intersubjetividad de aquellos hombres comprometidos en las situaciones de interacción social que constituyen nuestra realidad social.

${ }^{98}$ Citado por Gabás, R.J. Habermas: Dominio Técnico y Comunidad Lingüística. Barcelona Ariel, 1980 (p. 197). 